\title{
PREVALENCE OF ODONTOGENIC INFECTIONS AND THEIR RISK FACTORS AMONG THE GENERAL POPULATION OF HYDERABAD, PAKISTAN.
}

\footnotetext{
1. BDS, MSc

Assistant Professor

Department of Periodontology Isra Dental College, Hyderabad.

2. BDS, MSc

Assistant Professor

Department of Community Dentistry Isra Dental College, Hyderabad.

3. Pharm.D, Ph.D

Assistant Professor

Faculty of Pharmacy

University of Sindh, Jamshoro.

4. Pharm.D, M.Phil

Lecturer

Faculty of Pharmacy

Ziauddin University Karachi.
}

Correspondence Address:

Dr. Khurram Anwar

Department of Operative Dentistry

Isra Medical and Dental College.

arainpk_07@yahoo.com

Article received on:

18/02/2019

Accepted for publication:

$17 / 05 / 2019$

\section{Khurram Anwar ${ }^{1}$, Naveed Irfan ${ }^{2}$, Mudassar Iqbal Arain ${ }^{3}$, Saira Shahnaz ${ }^{4}$}

ABSTRACT... Objectives: Oral health performs a central part in general health which is associated with good oral hygiene. Teeth and their supporting (periodontal) structures are considered most important to oral health. Therefore, Most prevalent oral diseases such as odontogenic infections (dental caries, gingivitis, periodontal disease) gum disease, oral mucosal and congenital dental problems are foremost oral health dilemma in general population. Objective: The main objective of current study was to find out the Prevalence of odontogenic infections and their risk factors among the general population. Study Design: This is a descriptive cross sectional study. Setting: Dental patients who came to different dental clinical settings of Hyderabad, Pakistan. Period: August to December 2018. Material and Methods: A total of 300 patient's data were collected. In current study, the variables of interest are microbial odontogenic infections such as dental caries, gingivitis and periodontal disease were included in study. Following risk factors were explored: gender, age, residence, education level, disease duration, smoking, family history, and tooth paste habit. All information/data were personally collected by interview technique and oral cavity examination. The observational data were reported in the specific form and used descriptive statistics to find out the results. Results: A total of 300 dental patients having various infections such as gingivitis $(47 \%)$, dental caries $(20.7 \%)$ and periodontal infection (32.3\%) were reported in this study. Of these, 162(54\%) were females and $138(46 \%)$ of males. The most common age of patients i.e. $41.7 \%$ were from 41 to 60 years. Education status showed that $86 \%$ of the dental patients had education and $35.3 \%$ had family history of dental diseases. Factors such as mostly duration of diseases were $>6$ months $(33.7 \%)$ and almost $66 \%$ patients has habit of cleaning the teeths, However, Calculus and tarta deposited in $62.7 \%$ patients teeth. Smoking $(21.3 \%)$ and $46.6 \%$ patients used sweet foods on daily purpose. Moreover, amoxicillin most frequently prescribed antimicrobial agent $39 \%$ followed by metronidazole $32.7 \%$. Conclusion: Dental diseases are common public health problem among our society, poor oral hygiene \& dietary habits and deposition of calculus are associated factors for odontogenic infections. Moreover, prescribing pattern shows that Amoxicillin and Metronidazole has been considered as first-line treatment for oral infections. Therefore, oral hygiene education, dietary and proper cleaning of teeth habits and dental visit at early stage of disease should be recommended for patients to avoid and cure dental odontogenic infections.

Key words: $\quad$ Gingivitis, Odontogenic Infections, Periodontal.

Article Citation: Anwar K, Irfan N, Arain MI, Shahnaz S. Prevalence of odontogenic infections and their risk factors among the general population of Hyderabad, Pakistan. Professional Med J 2019; 26(11):1931-1936.

DOI: 10.29309/TPMJ/2019.26.11.3295

\section{INTRODUCTION}

Oral health performs a central part in general health which is associated with good oral hygiene. ${ }^{1}$ Teeth and their supporting (periodontal) structures are considered most important to oral health. Most prevalent oral diseases such as microbial dental infections or odontogenic infections (dental caries, gingivitis, periodontal disease), tooth wear, gum disease, oral mucosal and congenital dental problems are foremost oral health dilemma in general population. ${ }^{2,3}$ Particularly, odontogenic problems are polymicrobial infections. The oral cavity contain microbial flora of different population of microorganism. So, Poor oral hygiene is main cause of Oral diseases. ${ }^{4}$ Therefore, some microbes grow in oral cavity due to presences of saliva and eating particles. These microbes can cause to inflammation, infections 
and dental diseases in mouth. Most common microbial odontogenic infections are periodontitis and dental caries in our society.

Periodontitis is an inflammatory and infection of periodontitis tissues leads toward bone destruction. ${ }^{5,6}$ WHO reported that $31 \%$ Pakistani people has periodontitis, in which $18 \%$ has some type of periodontal problems. ${ }^{7,8}$ The primary stage of periodontal problems is bleeding and inflammation of gum known as gingivitis (gum inflammation). it is a common oral problem and plaque, bacterial growth in plaque and deposition of calculus are basic primary etiological factors of gingivitis. ${ }^{9}$ it represents as painful, swollen red and inflamed with bleeding gum and Untreated gingivitis can lead to periodontal disease. ${ }^{10}$

Dental plaque is origin of microbial community which found on matrix of polymers of microbial and salivary origin. If it is not removed regularly, it mineralized and change in calculus which can initiates the inflammation of periodontal disease. Later, small pus filled around the teeth \& there is loss of attachment of teeth and ultimately results in decay of tooth. Mostly Dental plaque deposits on the surface of tooth and it can make a cause of dental caries.

Dental caries is a progressive and chronic odontogenic infectious problem with a multifactorial etiology such as dry mouth, frequent intake of sweets, poor oral hygiene, and oral microbes that ferment sugars have to coexist and increase the risk of dental caries. Dental diseases cause pain, eating impairment, discomfort, loss of teeth \& difficulty in language development. ${ }^{11,12}$ These oral problems are more frequent in people having unhealthy life style poor oral hygiene, unawareness about oral health and low socioeconomic status.

These problems can be reduced by providing motivation of self care, awareness about oral hygiene education to people and Good oral hygiene is the key of an oral health and prevents almost $80 \%$ of all dental diseases. ${ }^{13,14}$ Therefore, the main objective of current study was to find out the Prevalence of odontogenic infections, management and their risk factors among the general population.

\section{MATERIALS AND METHODS}

This descriptive cross sectional study was carried out from august to December 2018 on 300 patients with dental problems who came to different dental clinical settings, Hyderabad, Pakistan. Simple random sampling was used to select the patients. A questionnaire was used regarding this study. Demographic details were asked from the patients. In current study, the variables of interest are microbial odontogenic infections such as dental caries, gingivitis and periodontal disease included in study. Following risk factors were explored: gender, age, residence, education level, diseases duration, smoking, family history, and tooth paste habit etc. All information/data were personally collected by interview technique and oral cavity examination. After collecting the information related to oral hygiene practices, and check the calculus and plaques of teeth though clinical examination. The observational data were reported in the performa and used descriptive statistics to find out the results.

\section{RESULTS}

Socio-demographic characteristics of sample population showed that a total of 300 dental patients of gingivitis, dental caries and periodontal were participated in this study. Table-I

A total of 300 dental patients of gingivitis (47\%), dental caries (20.7\%) and periodontal $(32.3 \%)$ were reported in this current study. Of these, 162(54\%) were females and 138(46\%) males. the majority of patients with gingivitis were diagnosed (47\%) followed by periodontal 32.3\%. The most common of patients (41.7\%) were from 41 to 60 years of age. Education status showed that $86 \%$ of the dental parent had education and $35.3 \%$ had family history of dental diseases.

The dental diseases and their associative risk factors are shown in Table-Il. Factors such as mostly time duration of diseases were above 6 months(33.7\%), almost $66 \%$ patients has habit of oral hygiene, frequency of teeth cleaning (one time teeth cleaning $48 \%$ ) and $66.3 \%$ patients 
used brush for teeth cleaning. However, Calculus and tarta deposited in $62.7 \%$ patients teeth.

Smoking (21.3\%) and dietary habit showed that $46.6 \%$ patients used sweet foods on daily purpose. These factors use to be significantly associated with the presence of gingivitis, caries, and other dental disease among patients

Table-III shows that amoxicillin most frequently prescribed antimicrobial agent $39 \%$ followed by metronidazole $32.7 \%$ and amoxicillin+ clavulanic acid $26 \%$.

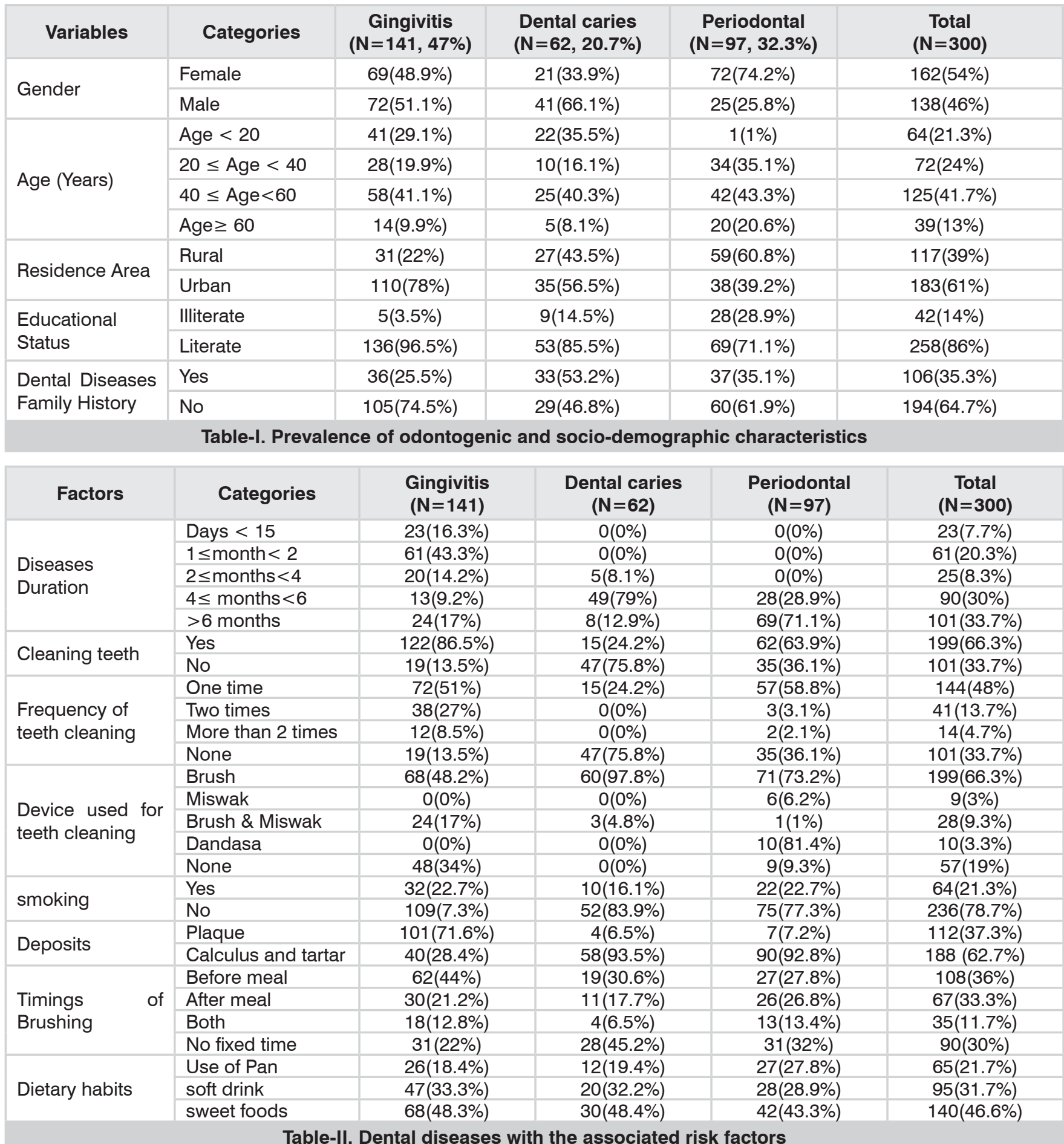




\begin{tabular}{|l|c|c|}
\hline \multicolumn{1}{|c|}{ Antimicrobial Agents } & No. of Patients (n=300) & Percentage \\
\hline Amoxicillin & 117 & $39 \%$ \\
\hline Metronidazole & 98 & $26 \%$ \\
\hline Amoxicillin+ clavulanic acid & 78 & $15 \%$ \\
\hline Cephalosporin & 45 & $7.3 \%$ \\
\hline Doxycycline & 22 & $6 \%$ \\
\hline Clindamycin & 18 & $3.6 \%$ \\
\hline Flouroquinolones & 11 & \\
\hline
\end{tabular}

Table-III. Prescribing patterns of antimicrobial in odontogenic patients

\section{DISCUSSION}

The current study showed that the prevalence of odontogenic infections particularly gingivitis, dental caries and periodontal dental diseases in Hyderabad region of Pakistan. Different dental diseases with demographic information indicated that there are A total of 300 dental patients, in which gingivitis (47\%), dental caries (20.7\%) and periodontal (32.3\%) were reported in study population. Of these, 162(54\%) were females and $138(46 \%)$ males. These results showed that females suffered more from dental diseases than males. This results is in contrast to a study of Chinese population which showed that there are equal prevalence rate gum disease between both gender ${ }^{15}$ The most common of patients (41.7\%) were from 41 to 60 years of age which is not agreed with the study of. Baranwal et al.18 found that mostly dental caries occurred in patients with age $>30$ years. ${ }^{16}$

This study described about frequency of associative risk factors of these diseases such as mostly time duration of diseases were above 6 months (33.7\%), Smoking (21.3\%) and dietary habit showed that $46.6 \%$ patients used sweet foods on daily purpose. These factors use to be significantly associated with the presence of gingivitis, caries, and other dental disease among patients

Albandar et al and Brothwell et al. also studies find that some demographic factors such as gender age, current smoker status are the basic risk factors of dental diseases. ${ }^{17,18}$ Khalifa et al was found that that gender, age, education status, tobacco use, infectious conditions are the important factors of tooth decay. ${ }^{19}$
During our study, we observed that Almost 66\% patients has habit of oral hygiene, frequency of teeth cleaning (one time teeth cleaning $48 \%$ ) and $66.3 \%$ patients used brush for teeth cleaning. However, Calculus and tarta deposited in $62.7 \%$ patients teeth. The calculus is a major risk factor for dental diseases. Calculus start local inflammation in surrounding of teeth which leads to infectious dental disease and also bleeding on brushing. These results described that calculus are related to oral hygiene, method of teeth cleaning and poor tooth brushing frequency. Bacterial growth and dental diseases start if oral cavity is not properly cleaned.

Similar studies were done by Umer et al. ${ }^{20}$ at Sargodha, Shaikh et al. ${ }^{21}$ at Larkana and Anwar et al. ${ }^{22}$ at Peshawar that described the status of oral health and oral hygiene practices was very poor. Mutamuliza et al. ${ }^{23}$ have found that age, education level, tooth brushing, smoking status are the main factors of periodontal disease.

This study also focused on prescribing pattern of antimicrobial agent. Prescribing pattern shows that several antimicrobial agents are prescribed for odontogenic infections. Antibiotics play key role for control of odontogenic infections. Amoxicillin and Metronidazole has been considered as firstline treatment for odontogenic infections. In amoxicillin resistant cases beta-lactamase-stable antibiotics should be used to the dental patient such as clindamycin or amoxicillin with clavulanic acid. ${ }^{24}$

\section{CONCLUSION}

Dental diseases are common public health problem among our society, poor oral hygiene \& 
dietary habits along with lack of dental visit at early stage of problems were the associated factors for odontogenic infections. Improper frequency and brushing timing are the main factors for calculus and plaque deposits that is the leading cause for gingivitis and periodontal disease. Moreover, prescribing pattern shows that Amoxicillin and Metronidazole has been considered as first-line treatment for oral infections.

Therefore, oral hygiene education, dietary and proper cleaning of teeth habits and dental visit at early stage of disease should be recommended for patients to avoid and cure dental odontogenic infections.

Copyright@ 17 May, 2019.

\section{REFERENCES}

1. Akram R, Khan MA. Prevalence of bleeding gums; In association with oral health practices in patients visiting Nishtar Institute of Dentistry, Multan, Pakistan. Professional Med J 2017; 24(12):1904-1908. DOI:10.17957/TPMJ/17.4233.

2. Amin M, Amanullah BM, Tarar AM. Dental caries, periodontal disease and their associated factors among patients visiting dental Teaching Hospital in Multan, Pakistan. JPDA. 2016 Jul; 25(03):99.

3. Butt AM, Ahmed B, Parveen N and Yazdanie N. Oral health related quality of life in complete dentures. Pak Oral Dent J 2009; 29(2):397-402.

4. Chrysanthakopoulos NA. Prevalence of gingivitis and associated factors in 13-16-year-old adolescents in Greece. Eur J Gen Dent 2016; 5:58-64.

5. Gangadhar V, Ramesh A, Thomas B. Correlation between leptin and the health of the gingiva: $A$ predictor of medical risk. Indian J Dent Res. 2011; 22(4):537-41.

6. Sperr $M$, Kundi $M$, Tursic $V$, Bristela $M$, Moritz $A$, Andrukhov O, Rausch $\square$ Fan X, Sperr WR. Prevalence of comorbidities in periodontitis patients compared with the general Austrian population. Journal of periodontology. $2018 \mathrm{Jan} ;$ 89(1):19-27.

7. http://www.who.int/mediacentre/factsheets/fs318/en/.

8. Bokhari SA, Suhail AM, Malik AR, Imran MF. Periodontal disease status and associated risk factors in patients attending a Dental Teaching Hospital in Rawalpindi, Pakistan. J Indian Soc Periodontol 2015; 19: 678-82.
9. Iqbal M pervaiz, Siddiqui M. Ismail Kausar Lubna, Iqbal $M$. Javed. Difference in plaque removal from buccal \& lingual surfaces of teeth by manual brushing. $P \mathrm{~J}$ M H S 2015:9(3):986-988.

10. Akram R, Khan MA. Prevalence of bleeding gums. The Professional Medical Journal. 2017 Nov 29;24(12):19048.

11. Mulu W, Demilie T, Yimer M, Meshesha K, Abera B. Dental caries and associated factors among primary school children in Bahir Dar City: A cross-sectional study. BMC research notes. 2014 Dec; 7(1):949.

12. Tafere $Y$, Chanie S, Dessie T, Gedamu H. Assessment of prevalence of dental caries and the associated factors among patients attending dental clinic in Debre Tabor general hospital: A hospital-based cross-sectional study. BMC oral health. $2018 \mathrm{Dec}$; 18(1):119.

13. Singh GP, Soni BJ. Prevalence of periodontal diseases in urban and rural areas of Ludhiana, Punjab. Indian J Community Med. 2005 Jan 1; 30(4):127-9.

14. Gualie YT, Tayachew AT. Assessment of knowledge, attitude, and practice toward oral hygiene among governmental secondary school students in Debre Tabor Town, Amhara Region, North Central Ethiopia 2018: Institutional-based cross-sectional survey. International Journal of Oral Health Sciences. 2018 Jul $1 ; 8(2): 92$.

15. Zhang J, Xuan D, Fan W, Zhang X, Dibart S, De Vizio $W$, et al. Severity and prevalence of plaque-induced gingivitis in the Chinese population. Compend Contin Educ Dent. 2010; 31(8):624-9.

16. Baranwal HC, Pandiar D, Singh TB. Pattern of dental carries among adults purvanchal region of Utter Pradesh, India. Int J Sci Res 2015; 4: 323-6.

17. Albandar JM, Streckfus CF, Adesanya MR, Winn DN. Cigar, pipe and cigarette smoking as risk factors for periodontal disease and tooth loss. J Periodontol. 2000; 71: 1874-81.

18. Brothwell DJ, Jay M, Schonwetter DJ. Dental service utilization by independently dwelling older adults in Manitoba, Canada. J Can Dent Assoc. 2008; 74: 161$161 f$.

19. Khalifa N, Allen PF, Abu-bakr NH, Abdel-Rahman ME, Abdelghafar KO. A Survey of oral health in a Sudanese population. BMC Oral Health 2012; $12: 5$. 
20. Umer MF, Farooq U, Shabbir A, Zofeen S, Mujtaba $H$, Tahir M. Prevalence and associated factors of dental caries, gingivitis, and calculus deposits in school children of Sargodha district, Pakistan. J Ayub Med Coll Abbottabad 2016; 28: 152-6.

21. Shaikh MA, Rajput F, Khatoon S, Shaikh MA. Prevalence of dental caries in BiBi Aseefa dental College, Larkana Areas. Pak Oral Dent J 2014; 34: 131- 4.

22. Anwar S, Rehman K, Khan M, Afridi, R. Body mass index and dental caries. J Khyber Coll Dent 2013; 3: 30- 3.
23. Mutamuliza J, Rwema F, Rulisa S, Ntaganira J. Prevalence and associated risk factors of periodontal disease among adults attending dental department in Rwanda Military Hospital (Rwanda): A cross sectional study. Dent Open J. 2015; 2: 105-11.

24. Jain MK, Oswal S. Antibiotics in dentistry-An art and science. Ann Dent Speciality. 2013; 1:20-5.

\section{AUTHORSHIP AND CONTRIBUTION DECLARATION}

\begin{tabular}{|c|c|c|c|}
\hline Sr. \# & Author(s) Full Name & Contribution to the paper & Author(s) Signature \\
\hline 1 & Khurram Anwar & $\begin{array}{l}\text { Concept, Data collection \& } \\
\text { write up }\end{array}$ & \\
\hline 2 & Naveed Irfan & Data collection & \\
\hline 3 & Mudassar Iqbal Arain & Write up & \\
\hline 4 & Saira Shahnaz & English gramdical & \\
\hline
\end{tabular}

